\title{
Designing and Assessing a Teaching Laboratory for an Integrated Land Use and Transportation Course
}

\author{
David King, Kevin J. Krizek, and David Levinson
}

\begin{abstract}
The intersection of land use and transportation policy is an important focus for all urban planners. This focus challenges the academic community to design effective courses that teach the concepts and professional skills required for professional experience. Integrated land use and transportation courses should help students develop interdisciplinary skills while becoming familiar with, for example, travel behavior and zoning policies. Laboratory courses as part of graduate curricula provide platforms to emphasize requisite planning skills. The associated pedagogy problem is devising laboratory assignments that are integrative, cumulative, practical, and interesting for students. This paper evaluates the success of laboratory segments of a land use-transportation course at the University of Minnesota in teaching concepts and skills that are central to planning practice. The lab design and student projects for a 4-year period are described; then a survey of former students is used to ask how central the concepts and skills from the course and lab are to the students' planning careers. The laboratory projects had students propose new development using air rights above existing (and sunken) urban freeways in the Twin Cities of Minnesota. The projects encouraged problem-based learning through reflexive planning processes, and the final projects were evaluated by practitioners and community leaders. Through analyses of the completed projects and survey responses, the authors demonstrate how these laboratory components serve multiple pedagogical goals.
\end{abstract}

Transportation and land use planning is increasingly taught as an integrated subject to address concerns such as air pollution, automobile dependence, congestion, and sprawl (1). Classroom lectures, case studies, and discussions work well to teach general concepts from the literature. However, such environments offer an inadequate forum to allow students to develop skills required in planning careers. Teaching practice-oriented planning skills in a structured laboratory component is a valuable tool to resolve the

D. King, Department of Urban Planning, University of California, Los Angeles, 3250 School of Public Affairs Building, Box 951656, Los Angeles, CA 90095. K. J. Krizek, University of Colorado, Active Communities/Transportation (ACT) Research Group, College of Architecture and Planning, University of Colorado, Campus Box 126, POB 173364, Denver, CO 80217-3364. D. Levinson, Networks, Economics, and Urban Systems (Nexus) Research Group, Department of Civil Engineering, University of Minnesota, 500 Pillsbury Drive SE, Minneapolis, MN 55455. Corresponding author: D. King, daveking@ucla.edu.

Transportation Research Record: Journal of the Transportation Research Board, No. 2046, Transportation Research Board of the National Academies, Washington, D.C., 2008, pp. 85-93.

DOI: 10.3141/2046-11 tension between learning and practice, especially as they relate to land use-transportation (LUT).

A master's degree in urban planning is aimed at training students for careers as planners. Yet classroom lectures offer few opportunities to gain hands-on experience with zoning codes, data analysis, geographic information systems (GIS), or the synthesizing of multiple planning issues into a polished presentation or report. To develop practice-oriented skills students need opportunities that challenge them to think through real-world planning issues, work with planning stakeholders outside a classroom, and practice valuable communication skills - a key aspect of a planner's work. Too often such learning takes place after students have moved into a planning career, not during their graduate studies.

Previous studies have surveyed planners about what skills recent graduates should have. At the top of nearly every survey are communication skills and the ability to navigate through the planning process (2-5). In practice, effective communication of planning goals and rationale is an integral bridge from planning knowledge to action. Treating the process of planning as part of the specialized knowledge planners need is part of reflective practice (6). Baum builds on reflective practice by arguing that the planning is a method of acting that can be learned only through doing. Yet he faults the academic training that planners receive for the failure to orient more courses toward planning practice as university programs "tacitly teach that planning is the same as research" (3, p. 21).

This paper describes and analyzes the experience of a laboratory component of a LUT course at the University of Minnesota. The laboratory used student planning projects of air rights developments over freeway trenches in the Twin Cities, St. Paul and Minneapolis, Minnesota. Air rights developments offer students a blank slate with which they evaluate, design, and propose site plans that require interdisciplinary skills and knowledge. Such developments also pose interesting constraints, such as how to knit new development into the existing community. At the end of the term, the students present their proposals to practitioners, community leaders, and local officials. The success of the course and lab in preparing students for planning careers was evaluated through a survey of the alumni about how central the course concepts and skills are to their current work.

The next section of this paper reviews the planning education literature. Then air rights developments are described as viable planning exercises, followed by details of the course concepts and lab assignments. Two sections of analysis follow, first an evaluation of the student air rights projects, and then an analysis considering the success of the course and lab in light of the alumni survey. The final section concludes and offers some suggestions to improve the design and focus of LUT courses and labs. 


\section{EDUCATIONAL NEEDS OF PLANNING PROFESSIONALS}

Scholars often call for increased specialization in planning education while maintaining generalized curricula (7). One common educational approach is a required internship as part of the degree program. Internships teach skills as they apply specifically to the employer; they often fail to teach planning skills as they relate to broader concepts. Laboratory courses in planning education present an opportunity for teaching an array of specialized topics because instructors can highlight the relationship between theory and practice. Although internships are a valuable tool for gaining professional experience, they are not designed specifically to relate to general planning education.

Handy et al. (5) surveyed transportation planning professionals and identified desirable skills and knowledge for planning careers. Their research asked whether transportation education was meeting the nontechnical needs of planning in light of the changes to the profession brought by substantial changes to the field that came about after the Intermodal Surface Transportation Efficiency Act of 1991 (ISTEA). ISTEA legislation placed greater emphasis on integrated transportation planning than did previous federal funding authorizations, with more focus on evaluating the effects of transportation plans on communities. What the researchers found is that communication skills are prized in prospective employees (5). Communication is critical because of the difficult nature of dealing with many planning issues, such as social equity concerns alongside traffic congestion and air pollution.

Other scholars call for communicative action. Ozawa and Seltzer (8) ask what planners should know and conclude that planning education needs to move closer to practice-oriented knowledge. In their analysis, they demarcated 45 separate categories of knowledge necessary for planners. Ernest Alexander (2) reconceptualized the work of Ozawa and Seltzer and identified three broad categories of planners' skills and competencies: theory, methods/skills, and judgment/good sense. Within the methods/skills category, he created four subfields: communication/presentation, analysis and methods, synthesis/creativity and design, and management/coordination. These methods/skills categories fit nicely with the categorizations described by Handy et al. This paper uses similar categories for analyzing the compatibility between the needs of educators and of planning practitioners. Two changes are made to Alexander's categories to allow for aligning the evaluation better with Handy and colleagues' desired skills. First, an evaluation of management/coordination is omitted. Second, analysis and methods are split into two categories. Data analysis is used to describe collecting data for describing the neighborhood conditions, and technical skills are used to describe the application of specific software (such as GIS) or specialized analysis, including traffic analysis.

Promoting planning practice within planning education is not a simple task. Planning educators are rightfully concerned that students learn the broad concepts and theory of planning rather than merely training for a vocation (9). One reason students are attracted to planning is the multidisciplinary nature of the field, but as the literature makes clear, learning how to use fundamental knowledge is just as critical as knowing it in the first place. Brooks et al. (10) argue that teaching planning practice is not as simple as placing students in applied situations; rather, teaching practice requires faculty participation to observe, assist, and evaluate student work and to provide a constructive critique that allows students to consider alternatives and future considerations.
One method of teaching practice to students is problem-based learning (11). Problem-based learning presents a controlled environment in which students are active in real-world planning issues under the guidance of instructors. Originally developed in the biomedical field, problem-based learning is a contextual approach that encourages students to learn from and with each other (12). Instructors act as facilitators rather than arbiters. A laboratory component to a LUT course serves as a problem-based learning opportunity in which students are presented with a complex planning problem under the supervision of the instructor. In the case of the LUT laboratory, students were assigned to work in groups so that they benefit from other students' knowledge and experience in a peer learning environment.

\section{AIR RIGHTS DEVELOPMENTS}

Air rights developments are ideal for a LUT laboratory because they offer a blank slate to apply planning concepts, creativity, and skills. Typically, with such developments investors purchase or lease the rights to develop above existing land from the rights holder, such as building owners, parking lot owners, or governments.

Air rights developments have a rich history, dating back to the Ponte Vecchio built in the 14th century in Florence, Italy. In the past century, Le Corbusier proposed building commercial and residential space above high-speed roadways. More recently, many communities in the United States have explored air rights development as a way to mitigate damage from freeway construction, but few projects have been successfully completed. Freeway trenches are deep physical divides that split neighborhoods and bring air and noise pollution to the surrounding communities. Building land bridges above freeways can address these concerns by bridging the spatial separation of neighborhoods, minimizing noise, and managing, though not reducing, air pollution.

In the Twin Cities, where the University of Minnesota campus is located, air rights present a natural opportunity because of the trench design of much of the Interstate freeways running through the cities; furthermore, there is long-standing interest in reclaiming the land lost to the freeways in the 1960s. In 1965, Minneapolis Congressman Donald Fraser proposed a federal grant to help build a platform over Interstate $35 \mathrm{~W}$ to replace a school and park that were demolished for the freeway construction (13), although ultimately nothing came of the proposal.

There are a few examples of air rights developments. In Duluth, Minnesota, a city park was built above Interstate 35 to connect downtown with the Lake Superior shoreline. In Seattle, the 5-acre Freeway Park was built in 1976. Freeway Park includes not only the namesake large urban park but a 21-story office building. Perhaps the most famous (or infamous) air rights development is the Boston, Massachusetts, Central Artery/Tunnel Project, in which more than $7 \mathrm{mi}$ of freeway was relocated to a tunnel. This allowed the city to reclaim 36 city blocks that were demolished for the previous freeway route and add 27 acres of open space to downtown Boston. On a smaller scale, Columbus, Ohio, built Union State Place on a land bridge across Interstate 670 . The freeway cap supports one-story buildings housing $27,000 \mathrm{ft}^{2}$ of retail space. Although Union State Place was small in scale, it was politically complicated and required coordinating the local community, private developers, local officials, and state and federal transportation officials. 


\section{CASE STUDY: DEVELOPING LABORATORY CONTENT}

The laboratory component was designed to complement a LUT course in the Urban and Regional Planning Program at the University of Minnesota, one of four "domain" courses offered. All planning students are required to take two of the domain courses during their graduate studies. The other domain courses include workforce and economic development, housing and social policy, and environmental and infrastructure planning. These courses are four-credit courses co-taught by one faculty member from the planning faculty and one from the outside field. This particular course draws interest from students outside the planning program, including civil engineering, geography, and architecture students. The students from outside planning proved to be fortuitous for creating a peer learning environment that featured several skills and perspectives.

The LUT course presents to students the motives and behaviors of the agents that exert their influence over the built environment. Three primary agents are individuals (households), firms (developers), and government agencies. In addition, planners act as a fourth agent responsible for communication and coordination among all agents as well as enforcing the standards and rules as required by regulations such as the zoning code.

The air rights project is designed to expose students to the perspective of each of the four agents through seven lab segments that relate to the course material and assignments. The seven lab segments are technical skills, data sources and analysis, design elements, zoning and comprehensive plan analysis, traffic analysis, benefit-cost analysis, and presentation and writing skills.

By using air rights development proposals in the Twin Cities during the 4 years of the lab, the cumulative impact of each year's student work grew. The peer learning process included each lab reviewing the work of previous labs. This greatly enhanced the quality and comprehensiveness of the proposals. Even though there were no site duplications during the 4 years of the laboratory, students learned about the process of developing plans and involving the communities from previous years.

\section{DESIGN OF LAB SEGMENTS}

The lab component of the course meets in a computer classroom instead of the lecture room. The air rights project is a collective project of about five students per group. Because graduate students come from a wide variety of professional and educational backgrounds, they bring a wide variety of skills to the lab. To help create effective peer learning groups, the first step of the lab component is to survey the students about their background and skills.
Such a survey would query specifically the student's experience and skill level with GIS, spreadsheet software such as Microsoft Excel, statistical analysis software such as SPSS, design- and drawingrelated skills, and experience using data from sources including the U.S. Census and local planning agencies. Ascertaining the breadth of skills each class brings allows the instructors to assign groups in a way that maximizes peer learning and working together. Spreading out the student's skills, such as having each group include someone with some GIS experience and someone familiar with data sources, means that every group has a roughly equivalent opportunity to excel at the final project.

In the experience of the LUT laboratory, the students who took the course each year brought sufficient experience with desirable skills to create effective teams with broad skill sets for the air rights development project. Table 1 presents the focus of the lab segments and relates them to planning issues from the lecture.

The lab is designed around planning concepts taught in lecture, allowing students to apply the course concepts to a practice-oriented planning application. Such an approach gives students the chance to practice their craft while developing their own impressions of the veracity of various planning issues. Because the lab project requires students to wear many different hats in the planning process, they discover the implications of their action from multiple perspectives. Having students assume many different roles in the process improves their understanding of planning consequences and highlights the need for effective and clear communication.

\section{DESCRIPTION OF LAB SEGMENTS}

The lab segments cover some technical skills and planning software applications, but because of time constraints, the LUT lab can offer little more than an introductory overview of these topics and applications. One challenge of the lab design is to introduce software without having the course become an instruction course. However, the LUT lab should provide plenty of practice using the software. To that end, lab design should include data sources used in planning practice and research. Air rights projects require evaluations of the community surrounding the proposed site. After the introductory lab meetings the students should be able to assess the planning issues facing their proposal plus understand the socioeconomic conditions of the community. In addition, because the students need to include transportation analysis in their projects, they need to know how to find and access transportation-oriented data.

The primary sources of easily available data are the U.S. Census, County Assessor's Office, and metropolitan travel surveys. Figure 1 shows one group's use of census data to describe the neighborhood surrounding its proposed project. The student group used GIS files

TABLE 1 Lab Segments and Planning Context

\begin{tabular}{lll}
\hline Lab Segment & Lab Focus & Context \\
\hline 1 & Technical skills introduction & \\
2 & Data sources & Jobs-housing balance and mode split \\
3 & Design elements & New urbanism \\
4 & Zoning and plan analysis & Standards, site design, and traffic calming \\
5 & Traffic analysis & Transportation demand management (TDM) and parking requirements \\
6 & Benefit-cost analysis & Pricing, impact fees, and taxes \\
7 & Presentation and writing & \\
\hline
\end{tabular}




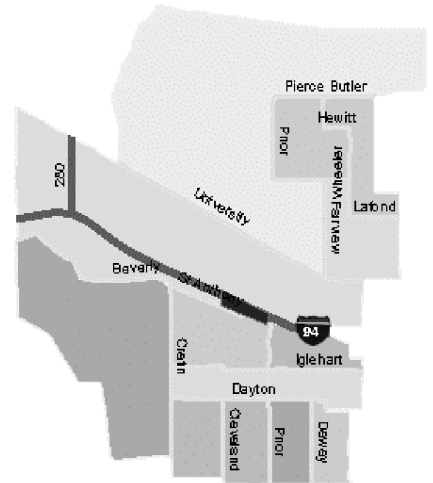

Median Household Income

$\$ 15,347.00$

$\$ 15,347.01-\$ 35,759.00$

$\$ 35,759.01-\$ 44,943.00$

$\$ 44,943.01-\$ 48,250.00$

$\$ 48,250.01-\$ 65,536.00$

St. Paul: $\$ 38,774$

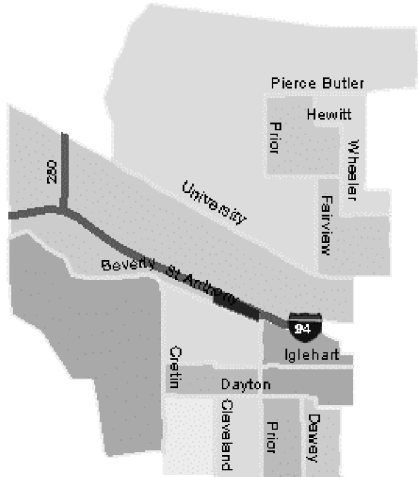

Percent of Commuters Who Drive Alone

$36 \%$

$37 \%-63 \%$

$64 \%-69 \%$

$70 \%-73 \%$

$74 \%-80 \%$

St. Paul: $69 \%$

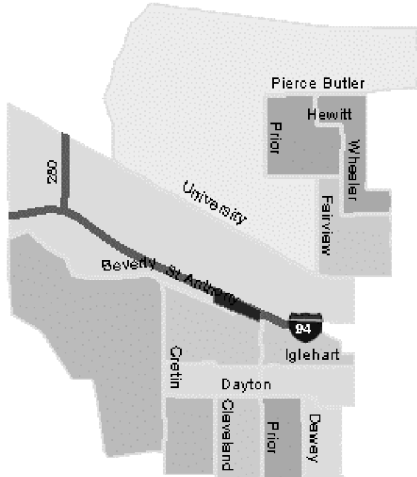

Percent OwnerOccupied Housing

$13 \%$

$14 \%-41 \%$

$42 \%-53 \%$

$54 \%-63 \%$

$64 \%-79 \%$

St. Paul: $55 \%$

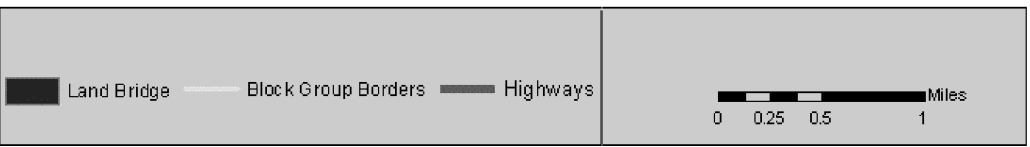

FIGURE 1 Demographic analysis of surrounding neighborhood. (Source: 2000 U.S. Census.)

from the U.S. Census website to create the maps in the figure. The maps show three things the students considered relevant to their planning goals: income, mode share, and homeownership. Students applied these data to their recommendations for addressing jobshousing balance and expected mode splits for any new development in the area. In this case, the students also realized the socioeconomic effects from the freeway trench. The southern side of the freeway has higher-income households and a predilection for driving alone to work. The homeownership map on the right shows that there are similar levels of ownership on the north and south sides, as seen by the shaded areas.

Another important piece of the students' work is how they present their work. In the case of Figure 1, the original maps were shown in full color, and the legend reflects the professionalism expected in the final projects. This group created a name and identity for its project, "Bringing Iris and Longfellow Together," that reflects not only the intent of the project but also the neighborhoods involved. These types of details enforce the connection between a course project and professional standards.

The third lab segment (Table 1) involves design elements of a site plan. At this point of the lab, the groups are expected to identify their proposed site and use the data from the previous lab segment to describe the demographic makeup of the community. Each team visits its site during this segment. The students should take notice of the design of the surrounding community to incorporate the desirable elements into their proposals. In the lab, students consider design approaches such as New Urbanist themes of neighborhood connectivity.

Figure 2 shows a typical development proposal from one of the final projects. This site is located on the west side of downtown Saint
Paul over Interstate 35E. In this example, the students designed a mixed-use development that was consistent with the city's Downtown Development Plan, the St. Paul on the Mississippi Development Framework, and the Capital Area Plan. In these plans, the city proposed a series of urban villages that adhere to strict planning principles while providing housing and commercial growth opportunities. For their projects, students are required to review and understand the applicable plans for their site proposals, the topic of the next lab requirement.

An alternative approach to the site plan is shown in Figure 3. This group represented its proposal from an aerial perspective. From

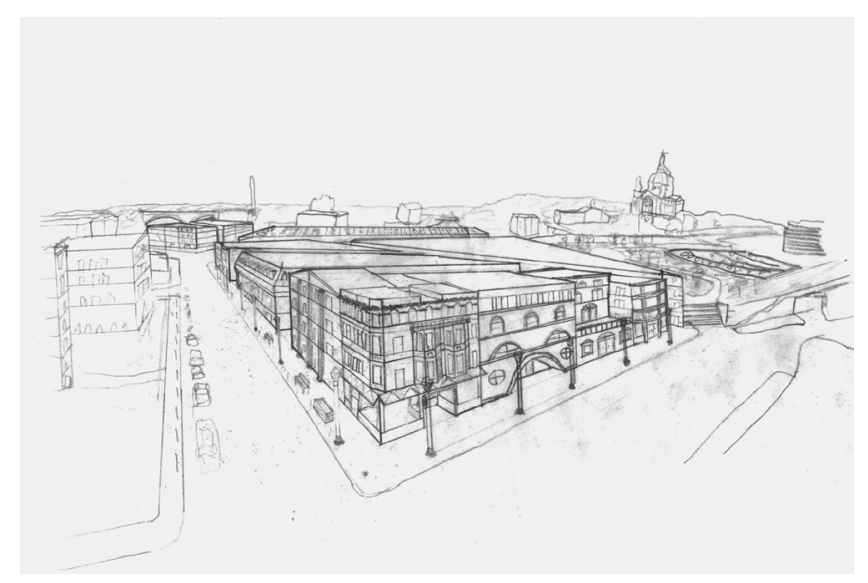

FIGURE 2 Typical site plan in downtown St. Paul overlooking Interstate 35E. 

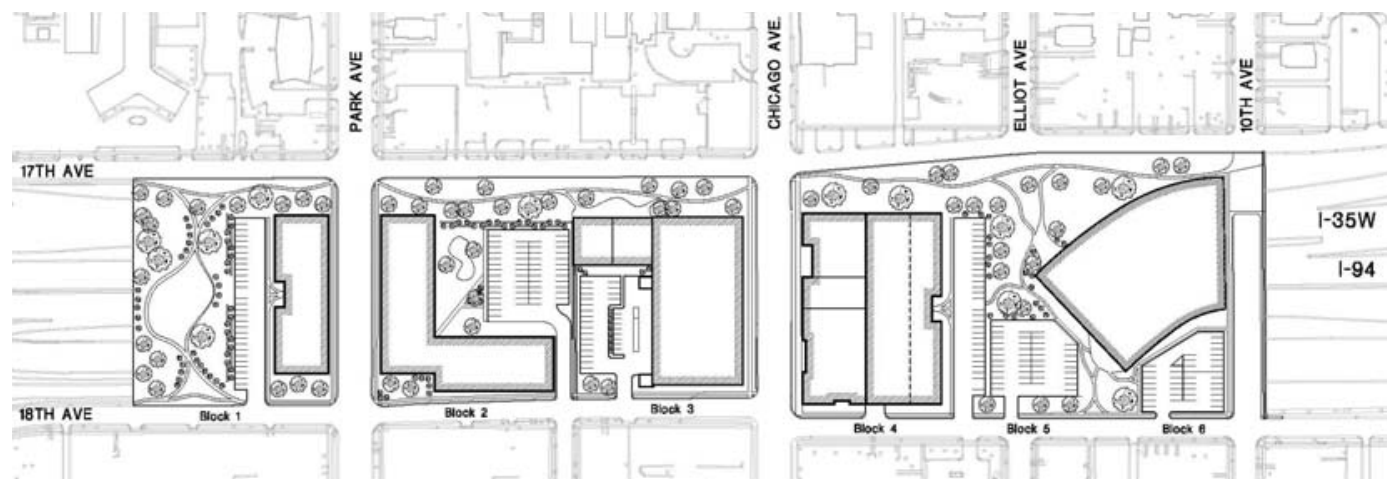

FIGURE 3 Aerial view of student-designed site plan.

this view the street grid, building alignment, and parking spaces are clearly seen. One advantage of this view is that the students are able to use existing land use maps, as was done here. The proposed development mostly maintains the existing street grid, but creates a superblock on the west side of the proposal. This superblock features a theater and substantial surface parking, although less parking than required under the zoning code. Here, the group argued for lowered parking requirements because of the access to transit and alternative modes of transportation, plus the proximity of this proposal to the employment opportunities of the downtown business district.

The student projects are incrementally developed week to week. This incremental approach not only allows the groups to focus better on their task at hand, but also improves the reflexive process of designing an appropriate site. In addition, the groups share with each other the work that they have accomplished. This reinforces the peer learning experience and should be facilitated by the instructor.

Figure 4 shows a before-and-after cross section of a proposed development. The existing conditions are reflected in the upper image and the new construction in the lower image. This proposal suggests transit connections and bicycle facilities to better serve the neighborhood. Such transportation ideas reflect the concepts students learn in class. Here, improved transit access and some commercial/retail space in the form of a coffee shop were added to the plan because of the input from the existing area plan and community preferences.

The fifth segment introduces traffic analysis using the ITE trip generation and parking generation manuals. Students are encouraged to think broadly about their proposals and use concepts such as transit-oriented design, traditional neighborhood design, and other transportation-related planning goals. These policies are designed to minimize traffic and provide alternatives to planning for automobiles.

For instance, transit stations are a common feature included in the air rights proposals (Figure 4). In particular, because the proposed developments are above the freeways, connecting the land bridge across the freeway to a new transit station at the freeway level allows residents of the development and surrounding community to connect directly to high-speed transit into downtown or other major job centers, reducing potential demand for cars and parking. It is an important part of the lab process that in addition to understanding how their proposals might affect local transportation issues, students also work with the surrounding community to gain community support for their proposals.

The sixth lab segment, the art and science of benefit-cost analysis, is briefly introduced. To produce rough estimates of costs, students look at published figures from similar developments including bridges or other air rights developments. The precision of these costs is less important than the full accounting of costs that go into a large development project. The benefits are estimated by using the county assessor's property tax information because air rights developments will generate new property taxes that do not currently exist. The intent of this segment is to entice students to think about all the costs and benefits of planning and how to evaluate individual projects.

The presentation and writing lab sessions include ample time for the groups to receive input from the instructor. An important feature of this segment is that the groups are forced to present their work in full to the class and instructors before the final presentation to
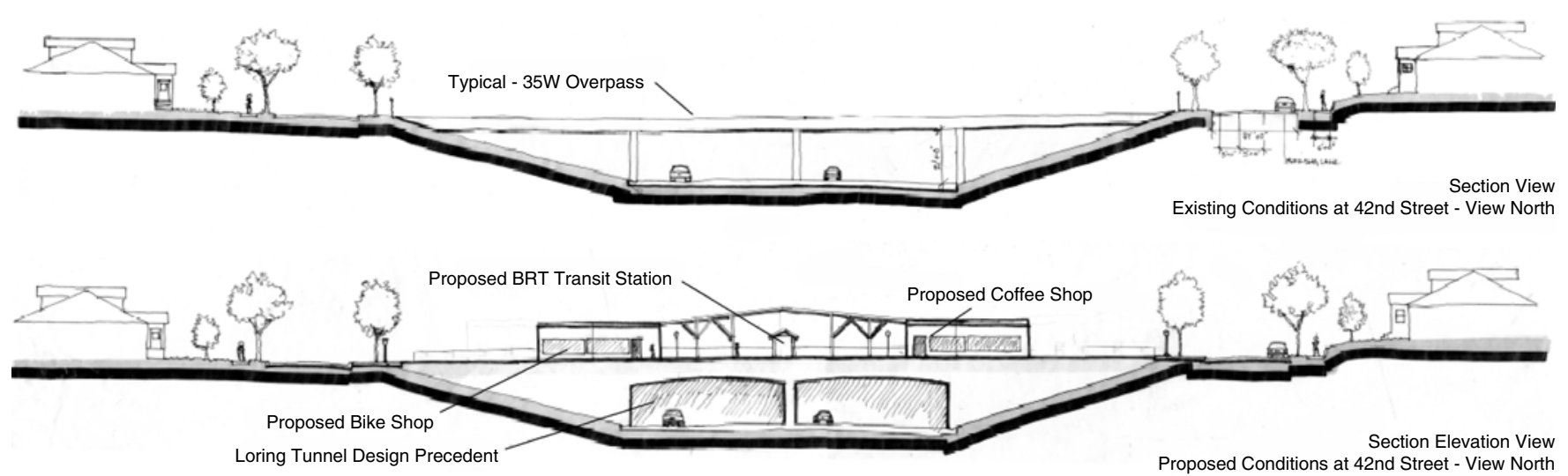

FIGURE 4 Before-and-after cross section of air rights development. 
invited officials. The peer learning experience requires that students are able to constructively critique each other's work. Mediating these critiques is the responsibility of the instructors, but the feedback the groups receive on their projects improves the final project while enforcing feedback loops that improve the content and clarity of the presentations.

The final project results in a formal presentation to an invited group of community leaders and professional planners. Students often express concern about presenting in front of an audience, but this is important because gaining experience in public speaking is a critical part of a planner's education. This type of role playing is beneficial for improving students' understanding of content, processes, and key skills necessary for planning professionals (14). The invited professionals are asked to evaluate the projects on four criteria: presentation quality, political feasibility, technical merits, and sensitivity to local issues.

\section{APPLICATION TO PLANNING EDUCATION}

Describing the content and process of the lab segments sheds some light on the skills that planning students develop through an integrated lab component. But the output from the laboratory should be evaluated against the expectations of the profession, not just the expectations of the instructors. Table 2 shows the weekly focus for each lab and the skill categories that each lesson develops as a primary focus.

Communication skills are emphasized in more than half of the lab sessions. The second half of the lab course is designed around communication skills, in particular working with people in the affected communities, writing effectively and clearly, and presenting work. Students benefit from knowing that their communication skills are evaluated by practitioners (and potential employers) from the beginning of the course. The instructors have a responsibility to clearly state their expectations from the beginning of the course, but emphasizing practice and dry runs of the final presentations greatly improves the overall quality of the work in ways that are obvious not only to the audience but also to the students who are presenting.

Data analysis and technical skills are emphasized in the early part of the lab course to encourage students to practice these skills. Although technical and quantitative skills tend not to be as highly valued as communication skills $(2,5,8)$, knowing these basic tools of the trade is necessary to effectively communicate and make informed judgments about planning policies. As such, technical and quantitative skills should not be deemphasized. The importance of communication skills for planning professionals, as argued by Handy et al., does not mean that more technical skills are any less desirable for planners. What is more likely is that the profession requires increased emphasis on personal interactions in addition to the current curricula. Expanding planning education is consistent with calls for 3-year programs by Friedmann (7) and others.

\section{PREPARING STUDENTS FOR PLANNING CAREERS}

To assess the effectiveness of the laboratory component in meeting the course goals, students of the course were surveyed during the period of the study. The questionnaire was administered in spring 2007 using an online service; the response rate was 24\%. (A link was sent to the survey, hosted at the Survey Monkey web service, to all alumni of the course for whom contact information was available93 in total. The contact information for approximately 10 recipients was invalid; a follow-up was done with the remaining 83-person sample with two requests. Overall, 20 responses were collected for a $24 \%$ response rate-an acceptable rate considering the length and purpose of the survey. Survey respondents are kept fully confidential so that no identifying characteristics, such as current employment, can be used.) Of the respondents, about half are in mainstream professional planning positions. The remaining respondents identified themselves as being in closely related fields including civil engi-

TABLE 2 Student-Instructor Activities and Skills by Week

\begin{tabular}{|c|c|c|c|c|c|}
\hline \multirow[b]{2}{*}{ Week } & \multirow[b]{2}{*}{ Lab Focus } & \multicolumn{4}{|l|}{ Skills Covered } \\
\hline & & Communication & $\begin{array}{l}\text { Data } \\
\text { Analysis }\end{array}$ & $\begin{array}{l}\text { Technical } \\
\text { Skills }\end{array}$ & $\begin{array}{l}\text { Design } \\
\text { Skills }\end{array}$ \\
\hline 1 & GIS applications & & $\mathrm{X}$ & $X$ & \\
\hline 2 & Data resources & & $\mathrm{X}$ & $\mathrm{X}$ & \\
\hline 3 & Comprehensive plans & $\mathrm{X}$ & & $\mathrm{X}$ & \\
\hline 4 & Zoning analysis & & $\mathrm{X}$ & & \\
\hline 5 & Traffic analysis & & $\mathrm{X}$ & $\mathrm{X}$ & \\
\hline 6 & Site visits & $\mathrm{X}$ & & & $\mathrm{X}$ \\
\hline 7 & Writing memos and reports & $\mathrm{X}$ & & & \\
\hline 8 & Benefit-cost analysis & & $\mathrm{X}$ & $\mathrm{X}$ & \\
\hline 9 & Design elements & $X$ & & & $\mathrm{X}$ \\
\hline 10 & Plan proposal & $\mathrm{X}$ & & & $\mathrm{X}$ \\
\hline 11 & Presentation & $\mathrm{X}$ & & & \\
\hline
\end{tabular}

NotE: Authors sent a link to the survey, hosted at the Survey Monkey web service, to all alumni of the course for whom we had contact information-93 in total. The contact information for approximately 10 recipients was invalid and the authors followed up with the remaining 83-person sample with two requests. Overall, 20 responses were collected for a $24 \%$ response rate- an acceptable rate considering the length and purpose of the survey. Survey respondents are kept fully confidential so no identifying characteristics, such as current employment, can be used. While the former students do not generally consider the land bridge project realistic, such ideas are gaining traction in some areas. One community in Los Angeles, for instance, is considering a project that would put a park on top of the 101 Freeway north of downtown. 


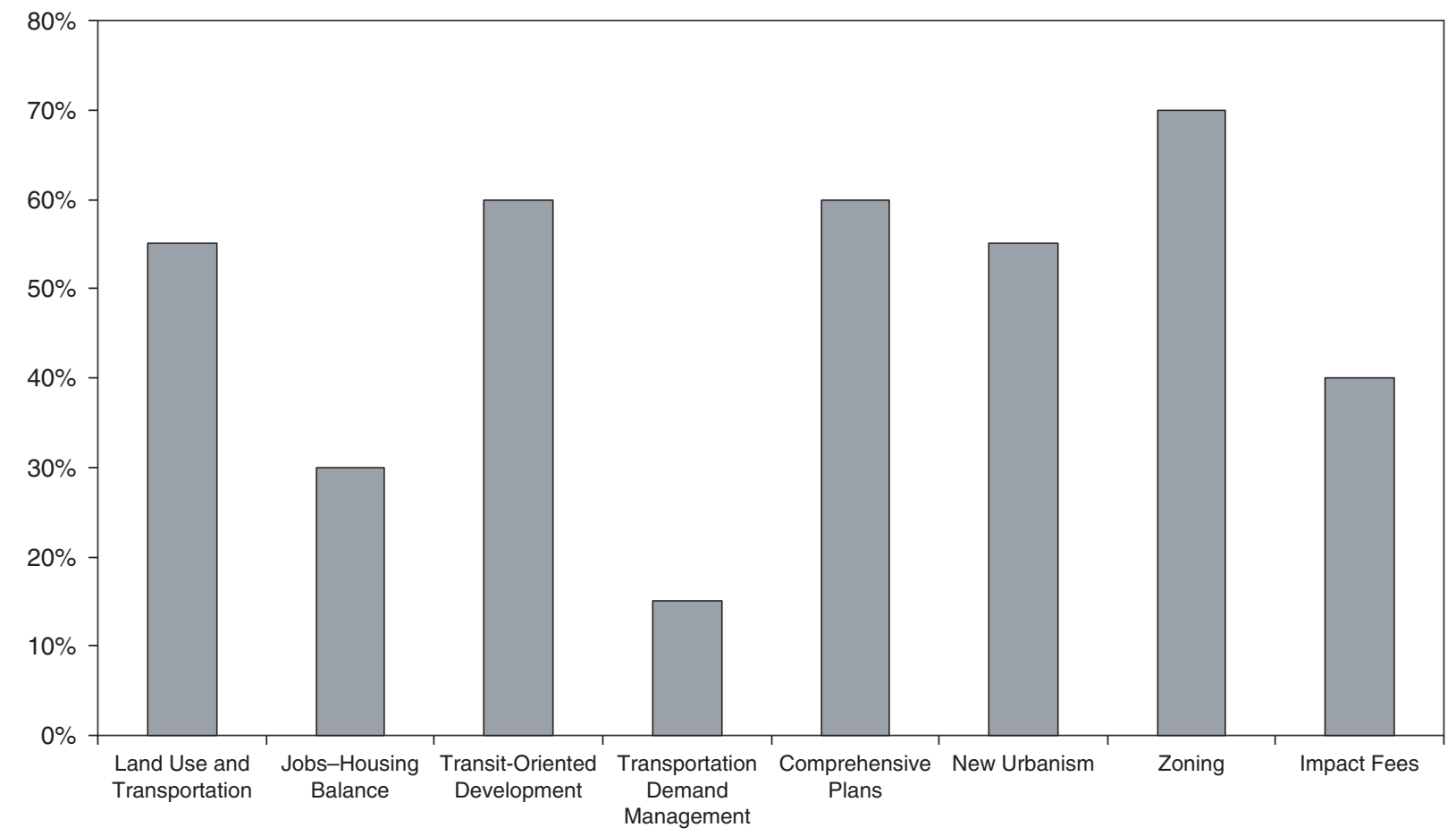

FIGURE 5 Concepts rated central or very central to work.

neering, community development, and policy analysis. The average tenure in their employment was about 2.5 years — an adequate amount of time to assess the value of the lab project on their current work. About two-thirds of the planning practitioners ranked land use and transportation as central or very central to their work.

Figure 5 shows responses when subjects were asked how central LUT planning was to their work along with the centrality of individual concepts from class. As expected, comprehensive planning and zoning are commonly used in practice. Transit-oriented develop- ment and New Urbanism are also rated as central for more than half of all respondents. These results suggest that the course teaches concepts that prepare students for practice. The more technical aspects of the course, transportation demand management and impact fees, did not rate as central for all alumni, but comments from the survey indicate that these noncentral issues are important for working with people in many fields, as planners often do.

The lab component was designed to apply these concepts to realworld planning problems using specific skills, however. Figure 6

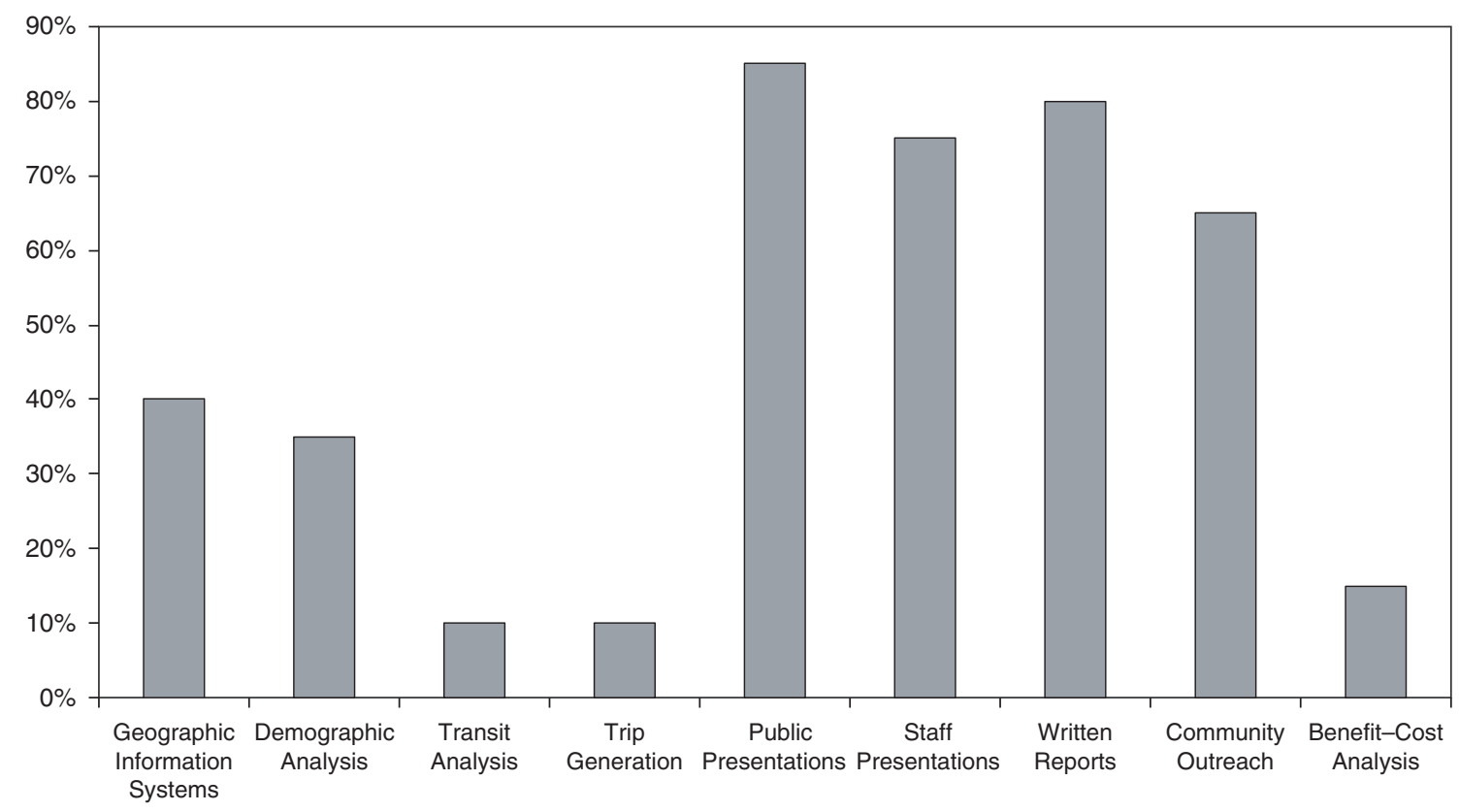

FIGURE 6 Lab skills rated central or very central to work. 
shows the percentage of respondents who rate skills taught in the lab as central to their job. Most striking about the responses is the importance of communication skills for planners and nonplanners alike. The responses indicated that in nearly all cases, both staff and public presentations along with written reports were central aspects of their jobs. These skills were recalled as critical pieces of the air rights project. Some former students commented that the lab project was the only opportunity in their graduate education to practice the presentation of a professional report and analysis - a somewhat startling finding!

Outside communication, there was less agreement about the value of other specific skills. Transit and trip generation analyses were rated as central to the career of only about $10 \%$ of respondents. This was an unexpected result considering that land use and transportation are important for most practitioners. However, this does not suggest that these skills are not valued. Some skills from the lab help planners work with many different professions. As one student explained, "My role in my job can be best described as project management. For any project, I am bringing together engineers, environmental consultants, architects, colleagues from neighboring cities, neighborhood groups, etc. It was helpful to learn how to work together with people from different fields and how to tap into the resources of areas I was unfamiliar with as planning (such as civil engineering)."

The land bridge project successfully brought together the skills and concepts from the course and offered a realistic planning exercise, although many thought land bridge development over freeways was unlikely. (Although the former students do not generally consider the land bridge project realistic, such ideas are gaining traction in some areas. One community in Los Angeles, for instance, is considering a project that would put a park on top of the 101 Freeway north of downtown.) One response was "Although the idea of a land bridge actually happening at the scale we proposed is a bit unrealistic, the land bridge process helped me develop some of the skills necessary to understand how to 'knit' a large development project into an adjacent community." Survey results echoed the sentiment that the most valued parts of the project were the interactions with community groups and neighbors of the proposed air rights developments. In addition, some students commented that the lab project was their first experience reaching out to interest groups and community organizations as planners. These comments highlight the importance of providing real-world applications in labs that allow students to meaningfully interact with stakeholders about a planning issue.

\section{CONCLUSIONS AND RECOMMENDATIONS}

Designing an effective laboratory component has taught a few important things that can be applied to lab design elsewhere. First, synergizing the lab component with the lecture content is difficult. The difficulty stems from the competing goals of practice versus theory. Lectures need to address the broad theories and concepts of planning, and labs are charged with practicing the actions of planning. To reconcile these two sides of education, the design and content of the lab sessions should reinforce the lecture materials, whether that is the jobs-housing balance or the effect of impact fees. The invited outside reviewers of the projects should be encouraged to ask about the planning policies covered in lecture by the instructors.

The second main conclusion is that an effective lab project must be flexible enough to incorporate the planning policies from the course.
Air rights developments are ideal because they are not limited by existing land use and transportation plans. Effective lab projects should maintain their autonomy while complementing existing community plans. The air rights development proposals generally were supported by the communities in the proposal areas. Community leaders have been active participants in the development of these student projects, in part because the community has been involved in the process. In at least one case the community has used the students' work to inform its own local area plan.

Similar to many teaching endeavors, developing an effective and successful lab component is a multiyear pursuit. Each year built on the previous year; the year-to-year improvements in content and output were dramatic. Continuity of the lab component was developed by recruiting a teaching assistant for the laboratory who previously completed the course. In addition, the previous year's presentations should be available to the current year's students to clearly establish what is expected and to encourage superior projects. The authors' experience supports that outcome; the quality and depth of the projects substantially improved year to year. Knowing that their work might be used in the future provides further incentives for students to excel.

Ultimately, the lab component of a LUT course should be designed for students to practice their craft and apply the lessons learned from lectures. This collection of case studies demonstrates how a lab can effectively bridge the gap between planning theory and planning practice while emphasizing the skills that professional planners expect students to have when they graduate. The laboratory environment should be an integral part of a planning education precisely because it can accomplish what a classroom cannot.

The survey suggests that the course introduced some concepts that are central to planning practice and some that, while not central, are valued because of the variety of fields with which planners work. Beyond these concepts, the lab project helped students develop and practice valuable communication skills. By far, communication skills are most valued by employers and employees. Planning is a job that requires community outreach, written reports, and many types of presentations. Some responses from former students suggest that they sought stronger technical training. However, as transportation and land use planning involve many subdisciplines, it is difficult to design a single course to teach specific software or specialized techniques.

Overall, it is found that a LUT course with a lab component well prepares students for careers in planning. Although the course and lab projects largely met their stated goals, there are some obvious areas of improvement. The good news is that these areas are easily fixed. The first area to concentrate on is communication skills in lab sections. These basic skills of writing and presenting work are critical to a practicing planner. Reinforcing the importance of such skills through meaningful interaction with planning stakeholders-by including practicing planners in the audience for project presentations, for instance-is an effective way to promote professional-quality communication. Of course, if there are other courses, labs, or client projects that emphasize writing and presenting research and other work, an LUT lab can be used to stress more specialized skills. This leads to the second area to concentrate on, which is coordinating course and lab design among faculty. Greater complementary offerings can maximize the development of valuable skills that are central to planning practice. Meeting the needs of planning practice in graduate education will ensure that future planners will be valuable and effective. 


\section{ACKNOWLEDGMENTS}

The authors thank each of the students in PA/CE 8202 from 2002 to 2005 as well as former teaching assistants for the class, including Andrew Johnson, James Lehnhoff, and Paul Mogush.

\section{REFERENCES}

1. Krizek, K. J., and D. M. Levinson. Teaching Integrated Land-Use Transportation Planning. Journal of Planning Education and Research, Vol. 24, 2005, pp. 304-316.

2. Alexander, E. R. What Do Planners Need to Know? Journal of Planning Education and Research, Vol. 20, 2001, pp. 376-380.

3. Baum, H. S. Teaching Practice. Journal of Planning Education and Research, Vol. 17, 1997, pp. 21-29.

4. Guzzetta, J. D., and S. A. Bollens. Urban Planners' Skills and Competencies: Are We Different from Other Professions? Does Context Matter? Do We Evolve? Journal of Planning Education and Research, Vol. 23 , 2003, pp. 96-106.

5. Handy, S., L. Weston, J. Song, and K. M. D. Lane. Education of Transportation Planning Professionals. In Transportation Research Record: Journal of the Transportation Research Board, No. 1812, Transportation Research Board of the National Academies, Washington, D.C., 2002, pp. $151-160$.
6. Schèon, D. A. The Reflective Practitioner: How Professionals Think in Action. Basic Books, New York, 1983.

7. Friedmann, J. The Core Curriculum in Planning Revisited. Journal of Planning Education and Research, Vol. 15, No. 2, 1996.

8. Ozawa, C. P., and E. P. Seltzer. Taking Our Bearings: Mapping a Relationship Between Planning Practice, Theory, and Education. Journal of Planning Education and Research, Vol. 18, 1999, pp. 257-266.

9. Fainstein, S. S. Planning Theory and the City. Journal of Planning Education and Research, Vol. 25, 2005, pp. 121-130.

10. Brooks, K. R., B. C. Nocks, J. T. Farris, and M. G. Cunningham. Teaching for Practice: Implementing a Process to Integrate Work Experience in an MCRP Curriculum. Journal of Planning Education and Research, Vol. 22, 2002, pp. 188-200.

11. Shepard, A., and B. Cosgriff. Problem-Based Learning: A Bridge Between Planning Education and Planning Practice. Journal of Planning Education and Research, Vol. 17, 1998, pp. 348-357.

12. Douvlou, E. Effective Teaching and Learning: Integrating Problem-Based Learning in the Teaching of Sustainable Design. CEBE Transactions, Vol. 3, No. 2, 2006, pp. 23-37.

13. Grant May Aid Platform Over 35W. Minneapolis Star, 1965.

14. Livingstone, I. Role-Playing Planning Public Inquiries. Journal of Geography in Higher Education, Vol. 23, No. 1, 1999, pp. 63-67.

The Transportation Education and Training Committee sponsored publication of this paper. 